\title{
Comentários incomodados
}

João Marcos Lopes*

FERRO, Sérgio. Arquitetura e trabalho livre. Organização e apresentação de Pedro Fiori Arantes. Posfácio: Roberto Schwarz. São Paulo: Cosacnaify, 2006. 456 p.

Não são absolutamente desconhecidas do público em geral as pretensões da construção civil afirmar-se como protagonista de um projeto de desenvolvimento nacional: a gritaria de um SINDUSCON (Sindicato da Indústria da Construção Civil do Estado de São Paulo), por exemplo, faz-se ouvir semanalmente entre as páginas de um grande diário paulistano, reclamando o reconhecimento do quanto a construção civil "contribui" para o desenvolvimento nacional, para a descompressão do desemprego, para a redução do descompasso econômico e para a realização bem sucedida dos destinos do país ${ }^{1}$. A ainda e por muito tempo necessária concorrência de extenso contingente de mão-de-obra na composição orgânica de seu capital faz da construção civil um fértil e vigoroso provedor de valor excedente, também vigorosamente disposto à extração na forma de mais-valia. De olho nessa "virtude" do canteiro de obras, o país, não poucas vezes,

* arquiteto, doutor em Filosofia, professor no Departamento de Arquitetura e Urbanismo da Escola de Engenharia de São Carlos - USP e associado da USINA - Centro de Trabalhos para o Ambiente Habitado.

1 Ao tratar do impacto do preço do gás de petróleo na economia e no setor da construção civil: "Afinal, dois terços de todos os investimentos realizados no país passam de uma ou outra maneira pelas mãos do setor da construção. Qualquer impacto maior nos seus custos poderia ter repercussões inflacionárias. Reverteria o cenário macroeconômico positivo, proporcionado pela deflação nos preços do atacado, e desaceleraria mais uma vez a queda dos juros" (SINDICATO DA INDÚSTRIA DA CONSTRUÇÃO CIVIL DO ESTADO DE SÃo PAULO. Janela: informe publicitário. Folha de São Paulo, São Paulo, p. A14, 14 maio 2006). Ao comentar o pacote da construção civil, de setembro de 2006 - e ensaiando recomendações aos candidatos à presidência da República: "Portanto, quem conseguir acabar com essa corrida de obstáculos (impedimentos para concessão de créditos consignados para aquisição de moradia, facilitação dos procedimentos burocráticos para concessão de financiamentos habitacionais, política de subsídios para famílias com renda menor que três salários mínimos, fortalecimento do segmento formal da construção civil etc.) dará uma grande contribuição ao desenvolvimento do país..." (SINDICATO DA INDÚSTRIA DA CONSTRUÇÃO CIVIL DO ESTADO DE SÃO PAULO. Janela: informe publicitário. Folha de São Paulo, São Paulo, p. A-15, 17 set. 2006). 
procurou ali aninhar, em boa medida, seu padrão piratininga de desenvolvimento nacional.

Por esta pista, e lá pelos anos de 1950, também a arquitetura se aproximaria programaticamente, como coadjuvante no setor da construção civil, para ensaiar sua participação no modelo de enfrentamento dos desacertos da nação - esta vítima predileta, desde tenra idade, da mais descarada endofagia bandeirante. Tratava-se de pensar a construção do país, de realizar a promessa de um progresso sempre adiado e, para tanto, aqui alinhar aquele ofício cujo núcleo, o projeto, só se faz possível se nele se reconhecer permanentemente a possibilidade de um futuro a ser construído coletivamente. Na contra-mão de um desenvolvimento dependente e combinado, aquele que se construiria autonomamente e na forma técnica apropriada à realidade que nos afligia. E nas entranhas do processo, presenciaríamos a intensificação do desenvolvimento das forças produtivas e o acirramento inexorável das tensões inerentes ao sistema de contradições presentes na evolução do capital.

Entretanto, algumas aporias insinuavam-se já nas origens do discurso e projeto desenvolvimentistas, arrastando para seus becos o protocolo de intenções que a arquitetura trazia a público lá pelo final dos anos 1950. Se Lúcio Costa recusava o termo "modernismo" - pelo desconforto com a palavra em moda e pela moda - é em favor da defesa de um projeto maior, mais consistente e mais cuidadoso que se estruturaria para assumir uma parcela de contrapeso mais significativo no esforço de reduzir o descompasso de nosso país em tempos modernos. Mas outros já falaram com maior propriedade sobre o assunto ${ }^{2}$.

Retomo a questão apenas para alcançar outra: o livro Arquitetura e trabalho livre, coletânea de textos do arquiteto, artista plástico e professor Sérgio Ferro, reconstitui um percurso de 40 anos de reflexão e escrita que recoloca, oportunamente, algumas questões já presentes no inventário do Dr. Lúcio - em sinal contrário, ressalte-se. Não que Sérgio cometa desaforos com o mestre: não denega seus esforços em reconhecer uma preocupação com a participação do "próprio obreiro" como "parte consciente na elaboração e invenção" da obra de arquitetura - como nos resgata Pedro Arantes, já no proêmio que apresenta a coletânea, da qual é responsável pela organização. Mas Ferro, desde logo, já fazia pé firme na idéia de que nosso

2 Ver, por exemplo, ARANTES, Otília. Lúcio Costa e a "boa causa" da arquitetura moderna. In: ARANTES, O. B. F.; ARANTES, P. E. Sentido da formação: três estudos sobre Antonio Candido, Gilda de Mello e Souza e Lúcio Costa. São Paulo: Paz e Terra, 1997. p. 113-133. 
desenvolvimento era falso e sustentado por uma realidade falseada e, a partir deste pressuposto, recusava-se a compor uma necessária relação entre desenvolvimento das forças produtivas e democracia. Neste palco, "a arquitetura representa um papel: é comediante", como diz ao final de um dos primeiros textos de Arquitetura e trabalho livre, "Arquitetura nova" (1967).

Já a caminho do final dos anos de 1960, Sérgio Ferro aparece, ao lado de Rodrigo Lefèvre e Flávio Império, todos arquitetos e professores, em trânsito já emburricado. Suas formulações e a arquitetura que dividia com o grupo - trama e urdidura, singularmente complexas e rústicas ao mesmo tempo, então tingidas com as cores da época - fizeram-no um "traidor". Estranhamente, podemos não compreender porque ainda assim poderão julgá-lo - como certamente se fará. Outros dirão, "trata-se de texto datado", exorcizando toda espécie de comprometimento daquele dito com o tempo de hoje $e^{3}$. No entanto, mesmo considerando que nossa raquítica democracia - parafraseando Lúcio Costa ao se referir à arquitetura moderna brasileira como "garota bem esperta, de cara lavada, e perna fina" - não impede o trânsito de nosso ir e vir como arquitetos, ainda assim somos forçados a admitir que vários dos argumentos de Sérgio Ferro são irritantemente atuais - registrados particularmente em "Arquitetura nova" (p. 47) e no rebatizado "A produção da casa no Brasil” (p. 61), o corte em esboço que aborta prematuramente a proposta que vem logo atrás: a arquitetura brasileira, "castrada", continua servindo de "agente de vendas" da mercadoria que ajuda a produzir (p. 50); os arquitetos,

alienados de sua função real por um sistema caduco, reagem dentro da faixa que o sistema lhes atribui, aprofundando, com isto, a ruptura entre sua obra e a situação objetiva a ser combatida. (p. 50-1).

repete-se, constantemente, inclusive com apoio de arquitetos e engenheiros 'progressistas' que, no Brasil, é importante a manutenção das características atuais da construção civil porque ela é um campo de absorção de mão-de-obra. (p. 101).

3 Especialmente no caso de "A produção da casa no Brasil", é quase ironia afirmar que se trata de "um texto datado", pelo fato de promover reflexão a partir de pesquisa que vinha sendo conduzida pelo prof. Carlos Lemos em 1969. Claro, tudo que se escreve deixa o tempo do que escreve para mergulhar no tempo do mundo. Mas é no mínimo equivocado o veredicto que condena o conteúdo de um texto como superado tendo por argumento apenas a data de sua produção. Basta que se dê uma olhadela ao redor: ora, continuamos na mesma - senão pior. 
Parece-nos o eco às avessas do que ainda apregoa o SINDUSCON.

Mas por que propor a atualidade dos textos de Arquitetura e trabalho livre? Com o aparente esfacelamento, no início dos anos 1980, do programa estabelecido e mantido pelo regime militar ao longo de mais de uma década, não ficava claro, também no calor da hora, que uma saída de tal natureza não deixaria o lugar liberado para as alvíssaras de um novo tempo anistiado. Os que viveram este período nas escolas de arquitetura (ainda não eram muitas!) podemos lembrar um certo arrefecimento daltônico das cores ideológicas de que o movimento estudantil, na época, ainda insistia em fazer persistir a intensidade: acreditava-se, ainda, no conluio revolucionário entre as vanguardas intelectuais e a classe trabalhadora, compondo, numa improvável coalizão gramsciana em versão trotskista, os vertedouros de uma possível nova ordem social. Mas os estudantes mais engajados rompiam alguns limites já claramente delineados pelo novo movimento operário que, naquele momento, retomava seus postos e já fazia bastante barulho: lembro-me de alguns colegas que, pretendendo emparelhar seus esforços nas portas das fábricas, voltavam exibindo hematomas conquistados justamente junto à classe operária com a qual pretendiam alguma aliança revolucionária e que dali os expulsava com o dedo em riste, mandando-os voltar para a "casa do papai".

No final dos anos 1970 e início dos 1980, pensando a Faculdade de Arquitetura e Urbanismo da USP, que demitira Sérgio Ferro em 1971 por "abandono de cargo" justamente no período em que estava preso, também era fácil não perceber que nossos ouvidos sofriam de espasmos de surdez. É certo que, naquela hora, operários, movimentos sociais e uma parcela da intelectualidade do país, ainda digerindo o jejum solitário de tanto tempo sem sequer poder ouvir, inventavam instrumentos menos contundentes porém mais eficazes para uma resistência inconformada à perspectiva sintomaticamente totalitária de um desenvolvimento periférico e perverso que nos tomava a farinha e o fermento do bolo com a promessa de reparti-lo quando crescesse - sabemos no que deu. Mas, voltando, a grande maioria de nós, alunos da FAU daqueles tempos, sequer tolerávamos o discurso encardido contra a "camarilha militar" que os militantes da LIBELU $^{4}$ insistiam em trazer às salas de aula, criando caso com os professores mais suscetiveis e os alunos menos engajados. 0 meio de campo acabou ficando ainda mais confuso - criando

4 Liberdade e Luta, corrente do movimento estudantil de linha trotskista, atuante no fim dos anos 1970 e ligada à Organização Socialista Internacionalista (OSI). 
oposições entre os trotskistas que chamavam colegas de "reformistas" e aqueles que não tinham nome porque os reformistas ignoravam os trotskistas - quando, em 1981, Vilanova Artigas, Paulo Mendes da Rocha e Jon Maitrejean retornaram à FAU, após o período de afastamento compulsório imposto pelo regime militar. Sabemos que Artigas não achava que o golpe militar havia obstruído a concepção de uma arquitetura visceralmente comprometida com o desenvolvimento radical das forças produtivas - e novamente é Pedro Arantes quem nos lembra uma certa sincronia ao mencionar a publicação de "Uma falsa crise", de Artigas, justamente no mesmo número da revista Acrópole ( $\left.\mathrm{n}^{\circ} 319,1965\right)$ que trazia "Arquitetura experimental" (p.37), onde era apresentado o trabalho do trio da chamada Arquitetura Nova (Ferro, Lefèvre e Império) e suas propostas para debate. Pareceme que, lembrando essa época, Artigas retornava retomando - sob outros contornos - o discurso de uma arquitetura em plena posse de seus rumos e caminhos.

Retomo o período para nele gravar a impressão que ainda preservo, do quanto o texto de Sérgio Ferro era, para nós, naquele momento, uma composição por fragmentos: alguns colegas gostavam de exibir seus textos elaborados "ao estilo de Sérgio Ferro". Alguns professores insistiam, nas aulas, em esparsas referências, a título de substrato para suas abordagens, a "0 canteiro e o desenho" (p.105) - um bocado escondido na sua versão de 1976 na revista Almanaque, posteriormente publicado pela Editora Projeto em 1979 e agora também presente na coletânea Arquitetura e trabalho livre. Também dela faz parte um texto de 1969 que, naquela época, nos era oferecido pelo Grêmio da faculdade, o GFAU, em publicação de 1972 - "A casa popular", agora rebatizado de "A produção da casa no Brasil" (p. 61). Seu autor, após um ano de prisão e desligado da FAU-USP, havia deixado o país em 1971 e instalara-se em Grenoble, na França, onde passou a dar aulas na Escola de Arquitetura daquela cidade e dedicar-se à pintura. No geral, o que mais ouvíamos falar de Sérgio Ferro era o silêncio.

Principalmente quando Artigas retornou com Paulo Mendes e Maitrejean e o alarido de boa parte dos alunos, sequiosos por uma arquitetura que nos elevasse a alguma condição demiúrgica, abafava as então chamadas "chatices" de Sérgio Ferro. Daí, parece-me que o discurso da função positiva do desenho ganhava posição isolada, aparecendo apenas como construção de liberdade, de autonomia, ficando assim praticamente sem antagonista, sem a crítica sistemática de seu conteúdo ideológico e de sua condição de heteronomia como funcionalidade sistêmica inerente às dinâmicas do capital - este, um dos assuntos centrais de "O canteiro e o desenho" (p. 105), exposto 
a uma cuidadosa revisão do autor - "Sobre '0 canteiro e o desenho' ” (p. 321) -, também publicada na coletânea que comento.

Não denego, contudo, alguns esforços. Neste período, Rodrigo Lefèvre - que dava aulas no primeiro ano do curso desde seu retorno à FAU-USP em 1977 e que poderia eventualmente partilhar as questões de Sérgio Ferro e participar no ensaio de um contraponto mais sólido (falo isso do ponto de vista dos alunos) - já se ia afastando da Faculdade para sua ida sem volta à Guiné Bissau: faleceria ali, em 1983, vítima de um acidente automobilístico que surpreeendeu a todos na época. Mas em 1978, com Ermínia Maricato, Siegbert Zanettini e Walter Ono, entre outros, ministrava nosso curso "integrado" (uma velha história sempre reeditada nos cursos de arquitetura), ocupando nossas tardes com Projeto, Planejamento, Programação Visual e Desenho do Objeto. Levavam-nos para a periferia, propondo nosso encontro com as opções que nos pretendiam fazer ver. Mas o fio da meada parecia rompido, como também se rompera o cordão umbilical na gestação interrompida que nos era imposta como herança: estes procedimentos didáticos, naquele momento, eram o máximo de contraponto. No entanto, aquele também era o tempo em que novos movimentos entravam em cena, que prometia uma nova rodada de utopias também nos territórios da arquitetura e do urbanismo.

Mesmo numa compreensão fraturada, e já um pouco para além daquele período, o texto de Sérgio Ferro - particularmente "O canteiro e o desenho" (p. 105) - ainda continuava frisando, mesmo que às migalhas, o reverso da reafirmação de um caminho glorioso para os desígnios da arquitetura. Tais migalhas, somadas a excertos de aspirações anarquistas, conjuminações idealizadas de um corte político-assitencialista da ação do arquiteto engajado com as questões sociais, concepções estetizantes da miséria e do pobre - muito em voga, em tempos de Comunidades Eclesiais de Base - ou até mesmo certo inconformismo frente às opções que a prática da arquitetura apresentava naquele momento, levaram-nos - friso o "nos" - a compor uma espécie de caleidoscópio das idéias que Sérgio Ferro incubara com Flávio Império e, particularmente, Rodrigo Lefèvre. Além disso, há outras tradições que, saindo dos anarquistas e passando por John Turnner, ou partindo da antropologia e chegando à fusão "antropoteta" de Carlos Nelson Ferreira dos Santos, acabaram compondo outras vozes para o canto dissonante que se ensaiava já no início dos anos de 1980 . Acho que o corte que faz o prelúdio dos textos do Sérgio Ferro no além-mar, ou seja na França, também impediu torná-los refratários, permitindo ajuntar aos seus ditos os tantos ditos de outras searas. Talvez tenha sido bom: a visão por fragmentos contribuiu para a admissão de ou- 
tros fragmentos e ajudou a não transformar - o que imagino que Sérgio Ferro odiaria - a crítica em doutrina.

Dessa percepção descontínua da crítica de Sérgio Ferro associada a um sem número de referências as mais diversas, passamos a viver uma série de "experimentos localistas" considerando, aqui e ali, alguns aspectos que a crítica ao modo de produção da "forma da forma-mercadoria" articulava fragmentos de inconformismo e resistência: os Laboratórios de Habitação em algumas instituições de ensino superior - Faculdade de Belas Artes de São Paulo, num primeiro momento, PUC-Campinas e FAUSantos ou nas engrenagens de extensão da UNICAMP, posteriormente; o caminho voluntário de arquitetos e estudantes de arquitetura que se dirigiam à periferia para ali fundarem os primeiros passos de uma outra possível prática de ofício; a agremiação de profissionais em torno de organizações voltadas a atividades junto ao movimento popular; o desenvolvimento de técnicas construtivas que expunham diretamente o corolário formal ou conceitual da manufatura heterogênea - uma "arquitetura da terra" mecanizada, desde o CEPED na Bahia até os painéis cerâmicos e as abóbadas da UNICAMP, por exemplo -, até mesmo posturas diferenciadas frente às antinomias do desenho e à heteronomia do canteiro de obras que já faziam teimar uma outra composição não hierárquica entre arquitetos e operários; todas estas maquinações, certamente, interagiram e se alteraram, como a alquimia que tem, como fim último, a transformação do alquimista: lidávamos diretamente com aqueles a quem Sérgio Ferro gostaria de ter dedicado seu "0 canteiro e o desenho" (p. 105) - os trabalhadores da construção civil e seus usuários pobres. "Tratava-se”, como diz Roberto Schwarz no posfácio que integra a coletânea de Sérgio Ferro, "de democratizar a técnica, ou, também, de racionalizar a técnica popular por meio dos conhecimentos especiais do arquiteto" (p. 436). Estes "experimentos localistas" fizeram escola - literalmente - e organizaram uma extensa rede de profissionais que se engajaram no planejamento e na produção habitacional no país. Criaram a cultura da "assessoria técnica" aos movimentos de moradia, consolidaram uma postura mais "diluída”, digamos assim, da ação profissional do arquiteto, formaram professores, resgataram o problema da moradia como uma questão da arquitetura, etc. etc.

No entanto, essa época "heróica", de reconstrução de uma possível democracia, de novas relações entre poder e povo, de utopias que ainda não tinham lugar, parece que foi paulatinamente esgotando suas alternativas para dar lugar a um lugar sem utopias. Chegamos aos nossos dias com um operário no poder, à posse daquela estrutura técnico-burocrática que afirmávamos ser capazes de mudar ao som de nossas utopias e, meio abobados, percebemos que o poder é que tem o operário 
e aquela estrutura estatal é que se apropria de nossas utopias. Os movimentos populares que tanto gritaram nos anos 1980 parecem cada vez mais afônicos e atrelaram-se, em diversas instâncias, às ordens burocráticas de uma relação administrada. Transformamos nossas concepções fragmentárias de "arquitetura do trabalho livre" em "programas de governo", em "políticas públicas" de ocasião e as submetemos à ordem que desordena a legítima vontade que tínhamos de mudar.

Assim, chegamos hoje a tempos irônicos: a "cara lavada" daquela moça de "pernas finas” já não esconde o encardido, e tanto a arquitetura do Dr. Lúcio Costa como a nossa democracia já não têm vergonha de mostrar não serem assim tão asseadas. Novamente, citando Roberto Schwarz, parece um tempo em que "o êxito da esquerda foi pessoal e geracional, mas não de suas idéias, das quais ela se foi separando, configurando algo como um fracasso dentro do triunfo, ou melhor, um triunfo dentro do fracasso". Pior ainda, "talvez se pudesse dizer também que parte do ideário de esquerda se mostrou surpreendentemente adequado às necessidades do capital" (p. 438). Nestes novos tempos, a versão por fragmentos de uma "arquitetura do trabalho livre" sequer almeja mais compor um projeto para desenvolvimento de si mesma, quanto menos o do país, sucumbindo à carga despótica dos tempos de subsunção do capital produtivo ao capital financeiro - na sua forma de absoluto abstrato.

Numa carta a Adorno, justificando a não admissão de um candidato ao Instituto de Pesquisa Social que dirigia em Frankfurt, Horkheimer reclama que faltava ao pretendente aquele "olhar aguçado pelo ódio a tudo o que está no lugar" 5 . Uma "arquitetura do trabalho livre" ainda reclama por outros "instrumentos mais contundentes" e, em tempos de pax romana rediviva, restam-nos o gesto e as palavras: reinventadas, reinventam idéias, reinventam a possibilidade da experiência e reconquistam os sentidos da política. Que para isso venha a coletânea de Sérgio Ferro: não se trata de um manual ou de doutrina curada em concreto armado mas retomada no varejo de um debate que espanta a lógica reacionária do "faço o que posso" (uma "estética do possível"?) que desliza pela esteira das determinações econômicas que perversamente nos "roubam a fala": como disseram os situacionistas, "o que queremos, de fato, é que as idéias voltem a ser perigosas”.

5 WIGGERSHAUS, Rolf. A escola de Frankfurt: história, desenvolvimento teórico, significação política. Rio de Janeiro: DIFEL, 2002. p. 15.

6 INTERNACIONAL SITUACIONISTA. Situacionista: teoria e prática da revolução. São Paulo: Conrad Editora do Brasil, 2002. p. 72. 